\title{
PENGARUH SENAM DIABETES MELLITUS TERHADAP PENURUNAN KADAR GLUKOSA DARAH PADA WANITA PENDERITA DIABETES MELLITUS TIPE II DI PERSADIA RSUD PRINGSEWU TAHUN 2016
}

\section{EFFECT OF DIABETES MELLITUS EXERCISE ON BLOOD GLUCOSE LEVEL IN WOMEN DIABETES MELLITUS TYPE 2 IN PERSADIA HOSPITAL GOVERNMENT PRINGSEWU 2016}

\author{
Andri Yulianto \\ Sekolah Tinggi Ilmu Keperawatan (STIKes) Muhammadiyah Pringsewu Lampung
}

\begin{abstract}
ABSTRAK
Pada penderita diabetes mellitus responden terbanyak adalah wanita karena dipicu oleh adanya persentase timbunan lemak pada wanita lebih besar dibandingkan dengan laki-laki yang dapat menurunkan sensitifitas terhadap kerja insulin pada otot dan hati. Oleh karena itu perlu adanya penatalaksanaan untuk penyakit diabetes mellitus salah satunya dengan senam diabetes mellitus untuk menurunkan kadar glukosa darah. Tujuan penelitian ini adalah untuk mengetahui adakah pengaruh senam diabetes mellitus terhadap penurunan kadar glukosa darah pada wanita penderita diabetes mellitus tipe 2 di PERSADIA RSUD Pringsewu Tahun 2016. Desain penelitian Quasy Eksperiment dengan model Pre test and Post test Non-equivalent Group kontrol pada 44 responden, 22 pada kelompok intervensi dan 22 pada kelompok kontrol yang memenuhi kriteria inklusi diperoleh secara purposive sampling. Hasil analisis menggunakan uji paired-t test terdapat pengaruh yang bermakna glukosa darah pada wanita penderita diabetes mellitus sesudah diberikan senam diabetes pada kelompok intervensi dengan nilai $P$-value 0,000 dimana $P$-value $<0,05$. Hal ini menunjukan bahwa senam diabetes mellitus dapat menurunkan kadar glukosa darah pada wanita penderita diabetes mellitus tipe 2. Diharapkan bagi layanan kesehatan untuk menjadikan kegiatan senam diabetes mellitus sebagai intervensi menurunkan kadar glukosa darah agar tidak terjadi komplikasi.
\end{abstract}

Kata Kunci : diabetes mellitus, wanita, glukosa darah, senam diabetes mellitus

\begin{abstract}
Most diabetes mellitus patient are women. It is because percentage of fat in females larger than the males which can decrease sensitivity to insulin action in muscle and liver. Therefore it is necessary to the management of diabetes mellitus, one of them with diabetes mellitus exercise can decrease blood glucose levels.Purpose of this study was to determine effect of diabetes mellitus exercise with decreasing blood glucose level in women diabetes mellitus type 2 in PERSADIA Hospital Government Pringsewu year 2016. Study design used quasi experiment with pre-post test non equivalent control group approach. Sample were 44 respondents divide in 2 group each 22 control group and 22 treatment group, which used purposive sampling technique Statistical test results were using paired-t test show significant effect diabetes mellitus exercise with decreasing blood glucose level in women with diabetes mellitus $(\rho=0.000)<(\alpha=0.05)$. The conclusion that exercise can decrease blood glucose level in women with type 2 diabetes mellitus. Researcher suggest that health care should give exercise education for diabetes mellitus as intervention to decrease blood glucose levels to prevent diabetes complication.
\end{abstract}

Keywords: diabetes mellitus, women, blood glucose, diabetes mellitus exercise 


\section{PENDAHULUAN}

Diabetes mellitus merupakan kelompok penyakit gangguan metabolisme kronis yang ditandai peningkatan glukosa darah (hiperglikemia), disebabkan karena ketidakseimbangan antara supplai dan kebutuhan insulin. Insulin dalam tubuh dibutuhkan untuk memfasilitasi masuknya glukosa dalam sel agar dapat digunakan untuk metabolisme dan pertumbuhan sel. Berkurang atau tidak adanya insulin menjadikan glukosa tertahan di dalam darah dan menimbulkan peningkatan gula darah, sementara sel menjadi kekurangan glukosa yang sangat dibutuhkan dalam kelangsungan dan fungsi sel ${ }^{1}$.

Data dari studi global International Diabetes Federation (IDF) menunjukkan bahwa jumlah penderita diabetes mellitus pada Tahun 2012 mencapai lebih dari 371 juta orang. Data prevalensi diabetes mellitus pada Tahun 2013 telah mencapai 381,8 juta dimana ini memberikan indikasi mengkhawatirkan masa depan diabetes sebagai ancaman utama untuk pembangunan global $^{2}$. Dari data diatas peneliti menyimpulkan jumlah penderita diabetes mellitus di Dunia berdasarkan studi global International Diabetes Federation (IDF) telah terjadi peningkatan sebesar 371 juta dari
Tahun 2012 menjadi 381,8 juta pada Tahun 2013.

Diabetes mellitus tipe 2 menunjukkan lebih besar terjadi pada wanita karena pada wanita terdapat hormon estrogen yang efeknya adalah meningkatkan lemak dalam tubuh pada jaringan sub-kutis sehingga wanita cendrung memiliki lemak tubuh yang lebih banyak, lemak tubuh pada lakilaki adalah $>25 \%$ dan pada perempuan lemak tubuhnya adalah $>35 \%$. Pada penderita diabetes mellitus tipe 2 untuk mengatur kadar glukosa darah adalah dengan melakukan latihan jasmani yaitu senam diabetes mellitus ${ }^{3}$.

Latihan jasmani merupakan upaya awal dalam mencegah, mengontrol dan mengatasi diabetes mellitus. Latihan jasmani menyebabkan terjadinya peningkatan aliran darah, jala-jala kapiler lebih banyak terbuka sehingga lebih banyak tersedia reseptor insulin dan reseptor menjadi lebih aktif yang akan mempengaruhi terhadap penurunan glukosa darah pada pasien diabetes mellitus ${ }^{4}$. Senam diabetes mellitus dapat menyebabkan terjadinya peningkatan pemakaian glukosa oleh otot yang aktif, sehingga secara langsung senam diabetes mellitus dapat menyebabkan penurunan kadar glukosa ${ }^{5}$. 
Penelitian sebelumnya mengenai adanya pengaruh latihan fisik: senam aerobik terhadap penurunan kadar glukosa darah pada penderita diabetes mellitus tipe 2 di Wilayah Puskesmas Bukateja Purbalingga dan hasil dari penelitiannya adalah jenis kelamin perempuan lebih mendominasi jumlahnya yaitu sebesar 13 orang $(59,1 \%)$, sedangkan jenis kelamin lakilaki hanya 9 orang $(40,9 \%)^{6}$. Kemudian didukung oleh penelitian lain bahwa ada pengaruh durasi senam diabetes mellitus pada penurunan kadar glukosa darah pada penderita diabetes mellitus tipe 2 dan hasilnya adalah responden perempuan lebih banyak menderita diabetes mellitus dari pada laki-laki. Pada kelompok diabetes mellitus durasi 30 menit perempuan $(71 \%)$ dan pada laki-laki (28\%), untuk kelompok diabetes mellitus durasi 60 menit, perempuan (73\%) dan laki-laki $(7 \%)^{7}$.

Prasurvei yang dilakukan oleh peneliti melalui observasi dan data kehadiran di PERSADIA Rumah Sakit Umum Daerah Pringsewu pada tanggal 20 Februari 2016 didapatkan data penderita diabetes mellitus terjadi peningkatan dari 85 orang pada Tahun 2014 menjadi 110 pada tahun 2015. Terbanyak penderita diabetes mellitus di PERSADIA adalah wanita yang mencapai $70 \%$.

\section{METODE}

Penelitian ini menggunakan desain quasy experimen design, dengan bentuk pendekatan "Pre test and Post test Nonequivalent Group Control"8 dan dilakukan pada bulan April sampai Mei 2016 di wilayah kerja Puskesmas Pringsewu Lampung. Populasi dalam penelitian adalah seluruh wanita diabetes mellitus tipe 2 di PERSADIA Rumah Sakit Umum Daerah Pringsewu, yang berjumlah 77 orang menggunakan purposive sampling 9 . Metode pengumpulan data menggunakan pengamatan langsung terhadap aktivitas responden atau partisipan yang terencana dilakukan secara aktif dan sistematis dengan mengisi lembar observasi dari hasil pemeriksaan glukosa darah pada wanita penderita diabetes mellitus tipe $2^{10}$. Yaitu dengan hasil pre-test dan post-test yang menggunakan kelompok intervensi dan kelompok kontrol dan satu set alat GDS yaitu glukotest. Analisis dari penelitian ini dengan menggunakan uji paired-t test pada tingkat kemaknaan $95 \%(\alpha=0,05)^{8}$. 


\section{HASIL}

Hasil Penelitian sebagai berikut :

\section{Tabel 1}

Distribusi Rata-Rata Penurunan Kadar

Glukosa Darah Pre-tes dan Post-test

Diberikan Perlakuan Pada Kelompok

Intervensi dan Kelompok Kontrol Di

PERSADIA Rumah Sakit Umum Daerah Pringsewu Tahun 2016

\begin{tabular}{cccccccc}
\hline & \multicolumn{3}{l}{ Intervensi } & & Kontrol & $\begin{array}{c}\text { T- } \\
\text { tes }\end{array}$ \\
& N & $\begin{array}{c}\text { Mea } \\
\mathbf{n}\end{array}$ & SD & N & $\begin{array}{c}\text { Mea } \\
\mathbf{n}\end{array}$ & SD & P \\
& & & & & \\
\hline Pre- & 2 & 150,2 & 8,27 & 2 & 150,9 & 7,34 & .78 \\
test & 2 & 7 & 6 & 2 & 1 & 8 & 9 \\
Post & 2 & 137,1 & 6,04 & 2 & 151,0 & 7,02 & .00 \\
-test & 2 & 8 & 5 & 2 & 5 & 0 & 0 \\
\hline
\end{tabular}

Berdasarkan tabel diatas diketahui bahwa rata-rata penurunan kadar glukosa darah pada kelompok intervensi sebelum dilakukan senam diabetes mellitus adalah 150,2 dengan standar deviasi 8,27 sedangkan rata-rata penurunan kadar glukosa darah pada kelompok kontrol sebelumnya adalah 150,9 dengan standar deviasi 7,34 hasil uji statistik didapatkan nilai $\mathrm{P}=0,78$.

Pada setelah perlakuan, pengukuran kadar glukosa darah pada kelompok intervensi rata-ratanya 137,1 dengan standar deviasi 6,04 dan kelompok kontrol rata-ratanya 151,0 dengan standar deviasi 7,02 dengan nilai $\mathrm{P}=0,000$.

Dari data tersebut dapat disimpulkan bahwa tidak ada perbedaan rerata penurunan kadar glukosa darah pada saat sebelum perlakuan antara kelompok intervensi dan kelompok kontrol dengan nilai $\mathrm{p}>0,05$ sedangkan setelah perlakuan terdapat perbedaan yang signifikan antara kelompok intervensi dan kelompok kontrol dengan $\mathrm{p}<0,000$.

\section{PEMBAHASAN}

1. Penurunan kadar glukosa darah pada kelompok intervensi

Berdasarkan hasil penelitian diperoleh rata-rata kadar glukosa darah responden pada kelompok intervensi sebelum diberikan senam diabetes mellitus 150,2 dan rata-rata kadar glukosa darah responden setelah diberikan senam diabetes mellitus menjadi 137,1 . hasil uji statistik $P$-value didapatkan nilai 0,000 maka dapat disimpulkan bahwa ada perbedaan yang signifikan antara penurunan kadar glukosa darah pada pengukuran pertama dan pengukuran kedua pada kelompok intervensi.

Sejalan dengan hasil penelitian ${ }^{11}$ bahwa pada kelompok intervensi sebelum dilakukan senam diabetes mellitus terdapat nilai rata-rata 3,07 dan setelah dilakukan senam diabetes mellitus terdapat nilai rata-rata 1,56 terdapat perbedaan yang signifikan antara pengukuran pertama dan pengukuran kedua. Sedangkan menurut hasil penelitian yang dilakukan oleh ${ }^{12}$ 
yang menyimpulkan individu yang aktif memiliki kadar glukosa darah yang lebih rendah dibandingkan yang tidak aktif dan intervensi latihan dapat menurunkan resiko diabetes tipe 2 sebesar $46 \%$.

Sejalan dengan teori yang mengungkapkan bahwa aktivitas fisik dapat mengontrol gula darah. Glukosa akan diubah menjadi energi pada saat beraktivitas fisik. Aktivitas fisik mengakibatkan insulin semakin meningkat sehingga kadar gula dalam darah akan berkurang. Pada orang yang jarang berolahraga, zat makanan yang masuk kedalam tubuh tidak terbakar tetapi ditimbun dalam tubuh sebagai lemak dan gula. Jika insulin tidak mencukupi untuk mengubah glukosa menjadi energi maka akan timbul penyakit diabetes mellitus tipe $2^{13}$.

Menurut pendapat peneliti melakukan senam diabetes mellitus merupakan salah satu cara untuk menurunkan kadar glukosa darah pada penderita diabetes mellitus, karena pada saat melakukan latihan fisik seperti senam diabetes mellitus akan menyebabkan terjadinya peningkatan aliran darah, jala-jala kapiler lebih banyak terbuka sehingga lebih banyak tersedia reseptor insulin dan reseptor menjadi aktif yang akan berpengaruh terhadap penurunan glukosa darah pada pasien diabetes mellitus tipe $2^{4}$.

2. Penurunan kadar glukosa darah pada kelompok kontrol

Berdasarkan hasil penelitian diperoleh rata-rata penurunan kadar glukosa darah responden pada kelompok kontrol sebelum diberikan senam diabetes mellitus 150,9 dan ratarata penurunan kadar glukosa darah responden setelah diberikan senam diabetes mellitus menjadi 151,0 hasil uji statistik $P$-value didapatkan nilai 0,525 maka dapat disimpulkan bahwa tidak ada perbedaan yang signifikan antara penurunan kadar glukosa darah pengukuran pertama dan pengukuran kedua pada kelompok kontrol.

Sejalan dengan hasil penelitian sebelumnya bahwa pada kelompok tidak terpapar dengan senam diabetes mellitus (kontrol) tidak terdapat perbedaan yang signifikan antara pengukuran pertama dan pengukuran kedua kadar glukosa darah ${ }^{14}$. Sesuai denga teori bahwa manfaat dari senam diabetes mellitus adalah meningkatkan penurunan kadar glukosa darah, mencegah kegemukan, ikut berperan dalam mencegah kemungkinan terjadinya komplikasi dan meningkatkan kualitas hidup diabetisi ${ }^{5}$.

Dari hasil penelitian diatas bahwa tidak dilakukannya latihan fisik seperti 
senam diabetes mellitus tidak memiliki pengaruh terhadap penurunan kadar glukosa darah, karena pada saat olahraga resistensi insulin berkurang dan sebaliknya sensitivitas insulin meningkat, hal ini menyebabkan kebutuhan insulin pada penderita diabetes mellitus tipe 2 akan berkurang. Respons ini hanya terjadi setiap kali berolahraga $^{5}$. Orang yang tidak mempunyai kebiasaan olahraga dapat meningkatkan terjadinya diabetes mellitus 6,23 kali lebih besar dari pada orang yang mempunyai kebiasaan olahraga $^{15}$.

3. Perbedaan penurunan kadar glukosa darah pada kelompok intervensi dan kelompok kontrol

Rata-rata penurunan kadar glukosa darah pada kelompok intervensi sebelum dilakukan senam diabetes mellitus adalah 150,2 dengan standar deviasi 8,27 sedangkan rata-rata penurunan kadar glukosa darah pada kelompok kontrol sebelum adalah 150,9 dengan standar deviasi 7,34. hasil uji statistik didapatkan nilai $\mathrm{p}=0,789$. Pada post perlakuan, pengukuran kadar glukosa darah pada kelompok intervensi reratanya 137,1 dengan standar deviasi 6,045 dan kelompok kontrol reratanya 151,0 dengan standar deviasi 7,020 dengan nilai $\mathrm{p}=0,000$.
Kesimpulannya adalah tidak ada perbedaan rerata penurunan kadar glukosa darah pada saat sebelum perlakuan antara kelompok intervensi dan kelompok kontrol dengan nilai $P$-value $>0,05$, sedangkan setelah perlakuan terdapat perbedaan yang signifikan antara kelompok intervensi dan kelompok kontrol dengan nilai $P$-value < 0,000 .

Sejalan dengan hasil penelitian sebelumnya bahwa rata-rata penurunan kadar glukosa darah antara kelompok intervensi dan kelompok kontrol pada pengukuran pertama tidak terdapat perbedaan yang signifikan, sedangkan setelah perlakuan terdapat perbedaan yang signifikan antara kelompok intervensi dan kelompok kontrol ${ }^{16}$. Didukung oleh hasil penelitian yang lain bahwa adanya perubahan yang signifikan setelah dilakukannya senam diabetes mellitus ${ }^{17}$.

Zaman sekarang ini banyak penderita diabetes mellitus yang lebih fokus dan hanya mengutamakan pada penanganan diet dan mengkonsumsi obatobatan, padahal penanganan diet yang teratur belum menjamin akan terkontrolnya kadar glukosa darah, akan tetapi hal ini harus diseimbangkan dengan latihan fisik yang sesuai. Sebab jika penderita diabetes mellitus tidak melakukan aktifitas fisik seperti senam diabetes maka metabolisme otot yang 
terjadi hanya sedikit, sehingga pemakaian glukosa dalam darah berkurang, hal ini dapat menyebabkan penumpukan glukosa dalam darah sehingga kadar glukosa dalam darah tinggi ${ }^{3}$.

Teori mengungkapkan bahwa aktivitas fisik dapat meningkatkan sensitivitas insulin dan memiliki efek langsung terhadap penurunan kadar glukosa darah. Pendapat peneliti tentang tidak adanya perbedaan penurunan kadar glukosa darah sebelum perlakuan antara kelompok intervensi dan kelompok kontrol karena dari jumlah kedua kelompok yaitu 44 responden belum mengetahui jika senam diabetes mellitus sangat berperan dalam pengelolaan penyakit diabetes mellitus agar glukosa darah selalu terkontrol, dan adanya perbedaan penurunan kadar glukosa darah pada pengukuran pertama dan pengukuran

\section{DAFTAR PUSTAKA}

1. Tarwoto, et al., 2012. Keperawatan medikal bedah gangguan sistem endokrin.: CV. Trans Info Media: Jakarta

2. International diabetes federation, 2013. Idf diabetes atlas sixth edition. dari http://www.idf.org/sites/default/files/EN 6E_Atlas_Full_0.pdf

3. Sinaga, J. dan Hondro, E., 2011. Pengaruh senam diabetes mellitus terhadap kadar glukosa darah pada penderita diabetes mellitus tipe 2 di wilayah kerja puskesmas darusalam medan. Jurnal Mutiara Ners Vol. 1, No. 7. Januari 2012 kedua baik kelompok intervensi dan kelompok kontrol. Setelah diberikan perlakuan akan terjadi perbedaan yang signifikan rerata penurunan kadar glukosa darah antara kelompok intervensi dan kelompok kontrol dengan nilai $P$-value < 0,05 .

\section{SIMPULAN}

Ada pengaruh yang signifikan antara senam diabetes mellitus terhadap penurunan kadar glukosa darah pada wanita penderita diabetes mellitus tipe $2 \mathrm{di}$ PERSADIA Rumah Sakit Umum Daerah Pringsewu pada kelompok intervensi.

\section{SARAN}

Peneliti mengharapkan agar penelitian ini menjadi program kegiatan senam diabetes mellitus di PERSADIA Rumah Sakit Umum Daerah Pringsewu dalam menangani penderita diabetes mellitus tipe 2.

4. Soegondo, S., 2007. Edukator diabetes di Indonesia: ruang lingkup dan standar kerja. FKUI: Jakarta.

5. Soegondo, S. Soewondo, P. dan Subekti, I., 2009. Penatalaksanaan diabetes mellitus terpadu. Balai penerbit FKUI: Jakarta

6. Indriyani, P. Supriyantno, H. dan Santoso, A., 2007. Pengaruh latihan fisik; senam aerobic terhadap penurunan kadar glukosa darah pada penderita $d m$ tipe 2 di wilayah puskesmas bukateja purbalingga. Jurnal Media Ners Volume 1, Nomer 2, Tahun 2007, Hlm 49-99 
7. Santoso, T. B. dan Nugrahini, F., 2011. Pengaruh durasi senam diabetes mellitus pada penurunan kadar glukosa darah pada penderita dm tipe 2. Jurnal Kesehatan, ISSN 1979-7621, Vol. 4, No. 2, Desember 2011: 143-153

8. Dharma, k. k., 2012. Metodologi penelitian keperawatan: pedoman melaksanakan dan menerapkan hasil penelitian. CV. Trans Info Media: Jakarta

9. Notoatmodjo, S., 2010. Metodologi Penelitian Kesehatan. Rineka Cipta: Jakarta

10.Nursalam, 2013. Metodelogi Penelitian Ilmu Keperawatan: Pendekatan Praktis Edisi 3. Salemba Medika: Jakarta

11.Endriyanto, E. Hasneli, Y. Dewi, I,. Y. 2014. Efektifitas senam kaki diabetes mellitus dengan Koran terhadap tingkat sensitivitas kaki pada pasien diabetes mellitus tipe 2

12.Krista, 2007. Physical activity and the prevention of type 11 (noninsulin-dependent) diabetes. http://www.fitness.gov/diabetes.pdf

13. Betteng, R. Pangemanan, D. Mayulu, N., 2014. Analisis faktor resiko penyebab terjadinya diabetes mellitus tipe 2 pada wanita usia produktif di puskesmas wawonasa. Jurnal eBiomedik (Ebm), Volume 2, Nomer 2.

14.Utomo, O. M., 2012. Pengaruh senam terhadap kadar hlukosa darah penderita diabetes. Unnes Journal of Public Health, ISSN 2252-6781

15.Santoso, T. B. dan Nugrahini, F., 2011. Pengaruh durasi senam diabetes mellitus pada penurunan kadar glukosa darah pada penderita dm tipe 2. Jurnal Kesehatan, ISSN 1979-7621, Vol. 4, No. 2, Desember 2011: 143-153

16.Wahyu, K., 2011. Efek senam diabetes mellitus terhadap glukosa darah sewaktu pada penderita diabetes mellitus tipe 2

17.Febriana, 2010. Pengaruh senam diabetes mellitus terhadap penurunan kadar glukosa darah pada penderita diabetes mellitus tipe 2 di PERSADIA 